\title{
Determining water use of sorghum from two-source energy balance and radiometric temperatures
}

\author{
J. M. Sánchez ${ }^{1}$, R. López-Urrea ${ }^{2}$, E. Rubio ${ }^{1}$, and V. Caselles $^{3}$ \\ ${ }^{1}$ Applied Physics Department, School of Industrial Engineering, University of Castilla-La Mancha, Av. España, \\ s/n 02071 Albacete, Spain \\ ${ }^{2}$ Instituto Técnico Agronómico Provincial de Albacete and FUNDESCAM, Av. Gregorio Arcos, \\ s/n 02006 Albacete, Spain \\ ${ }^{3}$ Earth Physics and Thermodynamics Department, Faculty of Physics, University of Valencia, C/Dr. Moliner, no. 50, \\ 46100 Burjassot, Spain
}

Received: 7 April 2011 - Published in Hydrol. Earth Syst. Sci. Discuss.: 20 April 2011

Revised: 3 August 2011 - Accepted: 20 September 2011 - Published: 5 October 2011

\begin{abstract}
Estimates of surface actual evapotranspiration (ET) can assist in predicting crop water requirements. An alternative to the traditional crop-coefficient methods are the energy balance models. The objective of this research was to show how surface temperature observations can be used, together with a two-source energy balance model, to determine crop water use throughout the different phenological stages of a crop grown. Radiometric temperatures were collected in a sorghum (Sorghum bicolor) field as part of an experimental campaign carried out in Barrax, Spain, during the 2010 summer growing season. Performance of the Simplified Two-Source Energy Balance (STSEB) model was evaluated by comparison of estimated ET with values measured on a weighing lysimeter. Errors of $\pm 0.14 \mathrm{~mm} \mathrm{~h}^{-1}$ and $\pm 1.0 \mathrm{~mm} \mathrm{~d}^{-1}$ were obtained at hourly and daily scales, respectively. Total accumulated crop water use during the campaign was underestimated by $5 \%$. It is then shown that thermal radiometry can provide precise crop water necessities and is a promising tool for irrigation management.
\end{abstract}

\section{Introduction}

Understanding the surface actual evapotranspiration (ET) is essential for managers responsible for planning and managing water resources, especially in arid and semi-arid regions where crop water demand generally exceeds precipitation and irrigation from surface and/or groundwater resources is then required to meet the deficit. This is particularly important in areas where water usage is regulated due

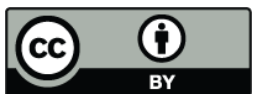

Correspondence to: J. M. Sánchez (juanmanuel.sanchez@uclm.es) to ecological protection programs, limited resources, or competitive demand (Piccinni et al., 2009).

Production of certain crops involves changes in land uses that might compromise water conservation strategies. This is of utmost importance in regions where determining crop water requirements specific to each crop is key to providing growers with information to select which crops to grow and determine the timing and quantity of irrigation events throughout the growing season (MARA, 2009).

Actual evapotranspiration varies regionally and seasonally according to weather conditions. The use of on-site meteorological data and crop coefficients enables the determination of crop water use. However, generic crop coefficients will not fulfill the need for precise irrigation applications, since they lack flexibility to account for temporal and spatial variation in crop water needs (Pinter et al., 2003), and specific crop coefficients need to be developed (López-Urrea et al., 2009a,b,c). This can be a limitation for providing spatially distributed regional ET information. The utility of the crop surface temperature to detect crop water stress has long been recognized, based on the fact that under stress conditions, the water transpired by the plants evaporates and cools the leaves, whereas in a water deficit situation, transpiration is scarce and canopy temperature increases (González-Dugo et al., 2006; Pinter et al., 2003; Gardner et al., 1992; Jackson et al., 1981). This theory has been used to develop indices that combine meteorological data with thermal remotely sensed information to provide relative measure of plant water status and health. The agricultural remote sensing literature abounds with examples of the application of thermal indices to schedule irrigations in various crops (e.g., Moran et al., 1994; Hatfield, 1983; Wang and Gartung, 2010).

Published by Copernicus Publications on behalf of the European Geosciences Union. 
Some authors such as Faver and O'toole (1989) or Choudhury and Idso (1985) used canopy temperature together with the Penman-Monteith equation to estimate crop ET. These authors reported high correlation between lysimeter ET and modeled ET from sorghum and wheat for selected days. Similar results were also found by Hatfield et al. (1983) and Jackson et al. (1983) but now focusing on a particular time of day.

Remotely sensed surface temperature as long been used too as a key input to determine ET as a residual of the land surface Energy Balance Equation (EBE) (e.g. Bastiaanssen et al., 1998; Su, 2002; Kustas and Norman, 1996; Pinter et al., 2003; Gavilan and Berengena, 2007). For example, Bashir et al. (2008) used the Surface Energy Balance Algorithm for Land (SEBAL) (Bastiaanssen et al., 1998), together with Landsat/ETM+ and MODIS images to estimate ET of a large irrigated sorghum area. Comparison with ET calculated using the water balance approach, for 4 selected days, showed an average absolute error around $0.9 \mathrm{~mm} \mathrm{~d}^{-1}$. However, SEBAL requires heterogeneity in surface moisture conditions. A dry or "hot" pixel, where $L E$ is assumed to be zero, and a wet or "cold" pixel, where $H$ is expected to be zero, are required. Due to the difficulty to bring together these two extreme conditions, SEBAL is not applicable to small crop fields (Bastiaansen et al., 1998). These and some other problems have been pointed out due to difficulties in quantification of aerodynamic resistances, especially under partial fraction cover conditions (Hall et al., 1992). Two-Source Energy Balance models may solve some of these limitations by allowing the estimation of soil and canopy contributions to the total energy fluxes, including evapotranspiration (Norman et al., 1995; Li et al., 2005). Sánchez et al. (2008, 2009) showed the potential of a simplified version of the two-source energy balance model (STSEB), when direct measurements of radiometric surface temperature are available, in a corn crop and a forest ecosystem, respectively.

In this paper, the STSEB model will be used together with thermal radiometry to determine ET values in a sorghum crop. Necessity to explore water use of sorghum as a potential biofuel source motivated the selection of this crop for the present study. In this work we focus on a forage sorghum field located in "Las Tiesas" experimental site in Barrax, Spain. A field campaign was carried out in the summer growing season of 2010 with the aim of studying water balance techniques and water necessities of energetic crops. A weighing lysimeter was placed in this site to register sorghum ET values, and two Infrared Thermal radiometers (IRT) were installed to measure surface temperatures.

The main objective of this study is to present this method as a simple and feasible technique to determine short and long-term crop water use from thermal infrared radiometry and ancillary meteorological data, under clear and cloudy sky conditions and covering different stages of the crop development, that could be further used as an alternative to weighing lysimeters required to determine irrigation needs or to calibrate crop coefficient based algorithms.
This paper is organized as follows. Information related to the study site, experimental set-up, and measured variables and parameters, is presented in Sect. 2. A summary of the main equations and aspects of the STSEB approach is given in Sect. 3. Section 4 shows the analysis of the measured radiometric temperatures and the estimated surface energy fluxes in the sorghum field. Modeled values of hourly and daily ET, together with the comparison with lysimeter ET measurements, are included in this Section. Finally, main conclusions are given in Sect. 5.

\section{Study site and materials}

This study was conducted during the summer of 2010 in the "Las Tiesas" farm, located between Barrax and Albacete (Central Spain). Its geographical coordinates are: longitude $2^{\circ} 5^{\prime} \mathrm{W}$, latitude $39^{\circ} 14^{\prime} \mathrm{N}$, and its altitude is $695 \mathrm{~m}$ a.s.l. (Fig. 1a). The climate is semi-arid, Temperate Mediterranean with $320 \mathrm{~mm}$ of annual rainfall, mostly concentrated in the spring and fall. Average mean, maximum and minimum temperatures are: $13.7,24.0$ and $4.5^{\circ} \mathrm{C}$, respectively. For a more detailed description of the climate of the area see López-Urrea et al. (2006).

The soil is classified as Petrocalcic Calcixerepts (Soil Survey Staff, 2006). Average soil depth of the experimental plot was $40 \mathrm{~cm}$, and is limited by the development of a more or less fragmented petrocalcic horizon. Texture is silty-clayloam, with $13.4 \%$ sand, $48.9 \%$ silt and $37.7 \%$ clay, with a basic $\mathrm{pH}$. The soil is low in organic matter and in nitrogen, and has a high content of active limestone and potassium.

To determine actual forage sorghum (Sorghum bicolor (L) Moench cv. H-133) ET, a weighing lysimeter was used (Fig. 1b). To schedule irrigation $\mathrm{ET}_{c}$ values were calculated from daily mass loss minus drainage loss and the mass added from irrigations and/or rainfall. In the lysimeter lost water was replaced, maintaining non-limiting soil water content. The lysimeter is located in the center of a $100 \mathrm{~m} \times 100 \mathrm{~m}$ plot, where sorghum sowed on 27 May in 2010 (DOY 147) in rows (N-S orientated) of $35-\mathrm{cm}$ spacing. Plant population was 21 plants $\mathrm{m}^{-2}$. Plant samples from three separate areas were obtained periodically to measure crop development. Leaf area index (LAI), fractional vegetation cover $\left(P_{\mathrm{v}}\right)$, and crop height $(h)$ were measured from the three samples. Sorghum reached a maximum crop height of nearly $5 \mathrm{~m}$, a maximum LAI of $11 \mathrm{~m}^{2} \mathrm{~m}^{-2}$, and the final harvest dry matter was around $2.7 \mathrm{~kg} \mathrm{~m}^{-2}$. According to MARM (2009), the average yield in Spain for irrigated forage sorghum results $3.8 \mathrm{~kg} \mathrm{~m}^{-2}$. Field harvest was on 23 September in 2010 (DOY 265).

The whole plot has a permanent sprinkler irrigation system with sprinklers placed on a grid of $15 \times 12.5 \mathrm{~m}$ that provide a precipitation rate of $8.6 \mathrm{~mm} \mathrm{~h}^{-1}$. The lysimeter container is $2.7 \mathrm{~m}$ long, $2.3 \mathrm{~m}$ wide and $1.7 \mathrm{~m}$ deep, with an approximate total weight of $14.5 \mathrm{Mg}$. Efforts were made to keep the 


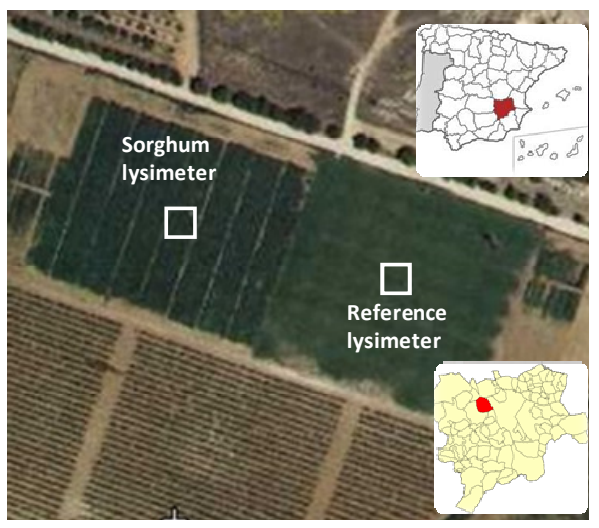

(a)

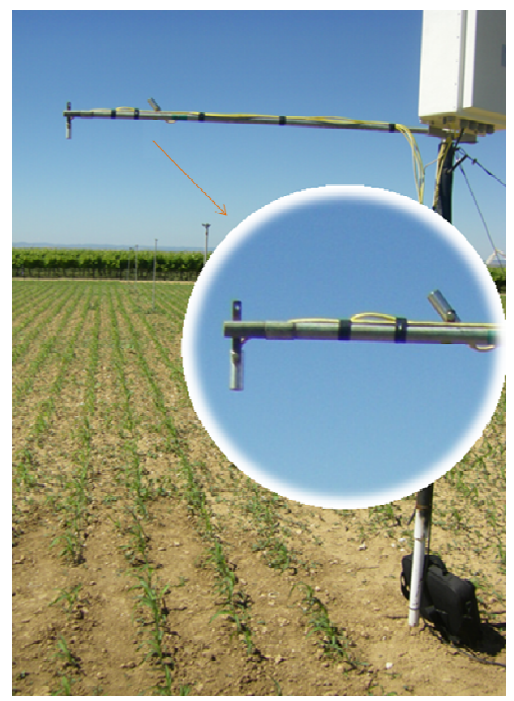

(c)

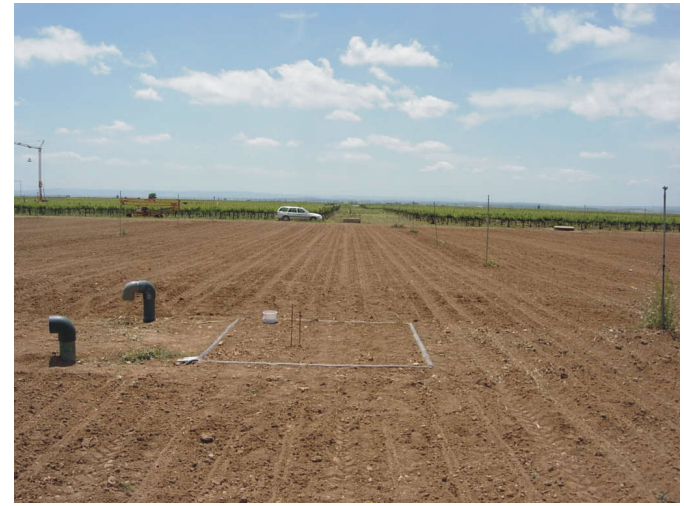

(b)

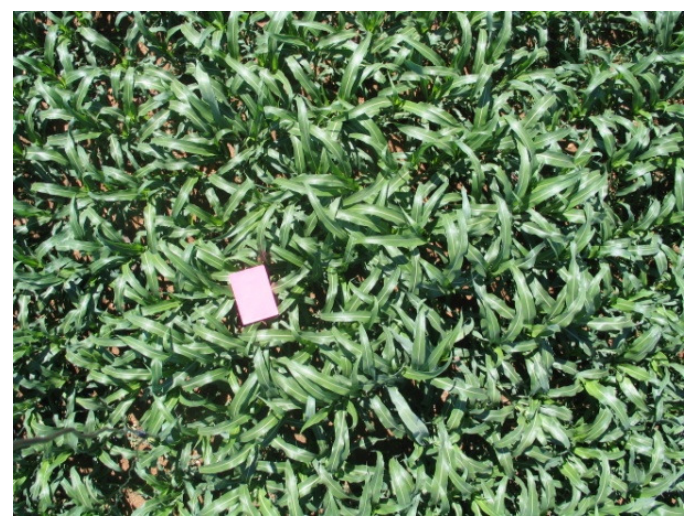

(d)

Fig. 1. (a) Location of the experimental site. (b) Lysimeter placed in the center of the sorghum field (picture from DOY 147). (c) Experimental assembly of the two Apogee IRTs over the incipient sorghum (picture from DOY 172). (d) Nadir view of the developed sorghum (picture from DOY 196).

crop inside the lysimeter at the same growth rate and plant population (21 plants $\mathrm{m}^{-2}$ ) as the crop outside to minimize edge effects. The lysimeter soil-containing tank sits on a system of scales with a counterweight that offsets the dead weight of the soil and the tank. The de-multiplication factor of the system is 1000:1. A steel load cell (model SB2, Epelsa ${ }^{1}$ Ind., S.L.) is connected to the system of balances. The balance-beam weighing system allows measurements of

\footnotetext{
${ }^{1}$ Trade and company names are given for the benefit of the reader and imply no endorsement by the authors.
}

ET in the lysimeter with a resolution of $0.04 \mathrm{~mm}$ equivalent water depth. The sample frequency was $1 \mathrm{~s}$, and a reading was registered by a datalogger (CR10X, Campbell Scientific Ltd., Logan, Utah, USA) every $15 \mathrm{~min}$. Additional information about the technical features of the lysimeter may be found in López-Urrea et al. (2006). The lysimeter readings were checked daily to identify individual readings that were not explained by natural processes of water input and loss. Data losses occurred during irrigation and precipitation events, weight and calibration verifications, and once, when the soil inside the lysimeter tank was cultivated. The 
resulting data were compiled to obtain the measurement of sorghum ET.

Starting on 19 June (DOY 174), radiometric surface temperature was measured, using an Apogee SI-211 thermal Infrared Radiometer (IRT). This radiometer has a broad thermal band $(6-14 \mu \mathrm{m})$ with an accuracy of $\pm 0.3{ }^{\circ} \mathrm{C}$, and $28^{\circ}$ field of view. It was placed at a height of $2 \mathrm{~m}$ above the canopy level at anytime, looking at the surface with nadir view (Fig. 1c,d). Sky brightness temperature was measured by a second Apogee radiometer pointing at the sky with an angle of $53^{\circ}$ (Rubio, 1998). These radiance values were used for the atmospheric correction of the surface temperature. IRTs were calibrated before the experiment. The calibration was done using a blackbody source (Model Land P80P). The calibration encompassed a wide range of temperatures $(-5$ to $50^{\circ} \mathrm{C}$ ), exceeding those experienced in the field. Unfortunately, measure of surface temperature failed after 9 September (DOY 249), reducing our study period to 75 days.

Solar irradiance (model CM14, Kipp \& Zonen Delft, Holland) and incoming long-wave radiance (model CG2, Kipp \& Zonen Delft, Holland), wind speed (model A100R, Vector Instruments Ltd., UK), air temperature and relative humidity (model MP100, Campbell Scientific, Logan, UT) were measured $2 \mathrm{~m}$ above local terrain at an adjacent weather station placed over a reference irrigated fescue grass surface

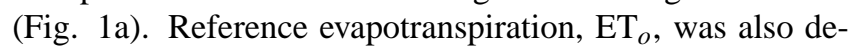
termined using the FAO56 Penman-Monteith method (Allen et al., 1998).

\section{Model description}

The net energy balance of the soil-canopy-atmosphere system is given by:

$R_{\mathrm{n}}=H+\lambda \mathrm{ET}+G$

where $R_{\mathrm{n}}$ is the net radiation flux $\left(\mathrm{W} \mathrm{m}^{-2}\right), H$ is the sensible heat flux $\left(\mathrm{W} \mathrm{m}^{-2}\right), \lambda \mathrm{ET}$ is the latent heat flux $\left(\mathrm{W} \mathrm{m}^{-2}\right)$, and $G$ is the soil heat flux $\left(\mathrm{W} \mathrm{m}^{-2}\right)$. Some other minor terms such as photosynthesis, advection or canopy storage have been neglected in Eq. (1). The effective radiometric surface temperature in the same system, $T_{\mathrm{R}}(K)$, can be obtained as a weighted composite of the soil temperature, $T_{\mathrm{S}}(K)$, and the canopy temperature, $T_{\mathrm{c}}(K)$ :

$T_{\mathrm{R}}=\left[\frac{P_{\mathrm{v}}(\theta) \varepsilon_{c} T_{\mathrm{c}}^{4}+\left(1-P_{v}(\theta)\right) \varepsilon_{s} T_{\mathrm{s}}^{4}}{\varepsilon}\right]^{1 / 4}$

where $\varepsilon_{\mathrm{c}}$, and $\varepsilon_{\mathrm{s}}$, are the canopy and soil emissivities, respectively, $\varepsilon$ is the effective surface emissivity, and $P_{v}(\theta)$ is the fractional vegetation cover for the viewing angle $\theta$. Using Eq. (2), values of $T_{\mathrm{c}}$ and $T_{\mathrm{s}}$ can be retrieved from a system of two equations with 2 unknowns if measures of $T_{\mathrm{R}}$ are available at two different view angles. However, an additional assumption is required when measures from the second view angle are missing (Norman et al., 1995; Sánchez et al., 2008).
In this work, a Simplified version of a Two-Source configuration of the Energy Balance (STSEB) (Sánchez et al., 2008) was used. According to this approach, the addition between the soil and canopy contributions (values per unit area of component) to the total sensible heat flux, $H_{\mathrm{s}}$ and $H_{\mathrm{c}}$, respectively, are weighted by their respective partial areas as follows:

$H=P_{\mathrm{v}} H_{\mathrm{c}}+\left(1-P_{\mathrm{v}}\right) H_{\mathrm{s}}$

where $P_{\mathrm{v}}$ (without a view angle argument) refers to the fraction cover at nadir view (i.e. $\theta=0^{\circ}$ ). In Eq. (3), $H_{\mathrm{s}}$ and $H_{\mathrm{c}}$ are expressed as:

$H_{\mathrm{c}}=\rho C_{p} \frac{T_{\mathrm{c}}-T_{\mathrm{a}}}{r_{\mathrm{a}}^{h}}$
$H_{\mathrm{s}}=\rho C_{p} \frac{T_{\mathrm{s}}-T_{\mathrm{a}}}{r_{\mathrm{a}}^{a}+r_{\mathrm{a}}^{s}}$

where $\rho C_{p}$ is the volumetric heat capacity of air $\left(\mathrm{J} \mathrm{K}^{-1} \mathrm{~m}^{-3}\right), T_{a}$ is the air temperature at a reference height $(\mathrm{K}), r_{\mathrm{a}}^{h}$ is the aerodynamic resistance to heat transfer between the canopy and the reference height at which the atmospheric data are measured $\left(\mathrm{s} \mathrm{m}^{-1}\right), r_{\mathrm{a}}^{\mathrm{a}}$ is the aerodynamic resistance to heat transfer between the point $z_{0 M}+d\left(z_{0 M}\right.$ : canopy roughness length for momentum, $d$ : displacement height) and the reference height $\left(\mathrm{s} \mathrm{m}^{-1}\right), r_{\mathrm{a}}^{s}$ is the aerodynamic resistance to heat flow in the boundary layer immediately above the soil surface $\left(\mathrm{s} \mathrm{m}^{-1}\right)$. A summary of the expressions to estimate these resistances can be seen in Sánchez et al. (2008). Equations (4) and (5) are taken from the parallel configuration of the TSEB model (Norman et al., 1995; Li et al., 2005), modified to take into account the distinction between $r_{\mathrm{a}}^{h}$ and $r_{\mathrm{a}}^{a}$. This distinction is necessary since transport of heat and momentum is not equally efficient over the canopy (Sánchez et al., 2008).

The partitioning of the net radiation flux, $R_{\mathrm{n}}$, between the soil and canopy is proposed as follows:

$R_{\mathrm{n}}=P_{\mathrm{v}} R_{\mathrm{nc}}+\left(1-P_{\mathrm{v}}\right) R_{\mathrm{ns}}$

where $R_{\mathrm{nc}}$ and $R_{\mathrm{ns}}$ are the contributions (values per unit area of component) of the canopy and soil, respectively, to the total net radiation flux. They are estimated by establishing a balance between the long-wave and the short-wave radiation separately for each component:

$R_{\mathrm{nc}}=\left(1-\alpha_{\mathrm{c}}\right) S+\varepsilon_{\mathrm{c}} L_{\mathrm{sky}}-\varepsilon_{\mathrm{c}} \sigma T_{\mathrm{c}}^{4}$
$R_{\mathrm{ns}}=\left(1-\alpha_{\mathrm{s}}\right) S+\varepsilon_{\mathrm{s}} L_{\mathrm{sky}}-\varepsilon_{\mathrm{s}} \sigma T_{\mathrm{s}}^{4}$

where $S$ is the solar global radiation $\left(\mathrm{W} \mathrm{m}^{-2}\right), \alpha_{\mathrm{s}}$ and $\alpha_{\mathrm{c}}$ are soil and canopy albedos, respectively, $\sigma$ is the StefanBoltzmann constant, and $L_{\text {sky }}$ is the incident long-wave radiation $\left(\mathrm{W} \mathrm{m}^{-2}\right)$. Note that longwave emission from one component over the other is not accounted since no direct coupling is considered between soil and vegetation in the STSEB scheme (Sánchez et al., 2008). 


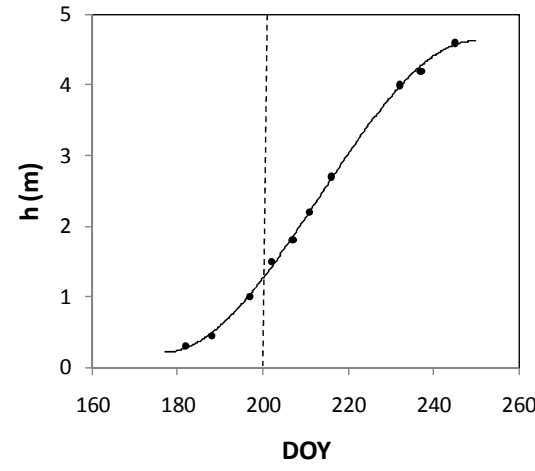

(a)

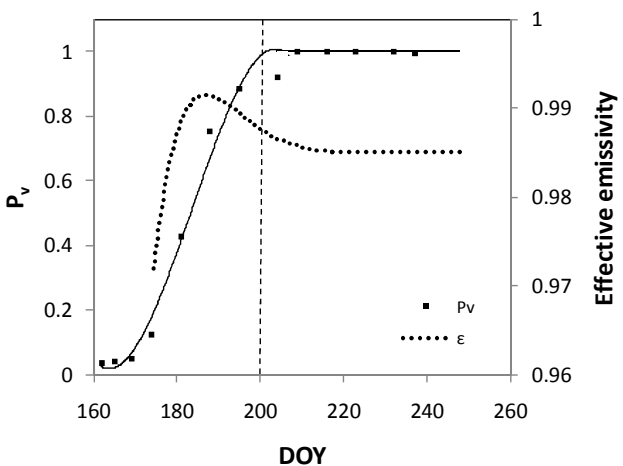

(b)

Fig. 2. (a) Evolution of the modelled sorghum height during the experiment (line) superposed to the field measurements (dots). (b) Evolution of the modelled $P_{\mathrm{V}}$ during the experiment (line) superposed to the field measurements (dots), together with the modelled effective emissivity.

A similar expression is used to combine the soil and canopy contributions, $\lambda \mathrm{ET}_{\mathrm{s}}$ and $\lambda \mathrm{ET}_{\mathrm{c}}$, respectively, to the total latent heat flux:

$\lambda \mathrm{ET}=P_{\mathrm{v}} \lambda \mathrm{ET}_{\mathrm{c}}+\left(1-P_{v}\right) \lambda \mathrm{ET}_{\mathrm{s}}$

According to this framework, a complete and independent energy balance between the atmosphere and each component of the surface is established, from the assumption that all the fluxes act vertically. In this way, the component fluxes to the total latent heat flux can be written as:

$\lambda \mathrm{ET}_{\mathrm{c}}=R_{\mathrm{nc}}-H_{\mathrm{c}}$

$\lambda \mathrm{ET}_{\mathrm{s}}=R_{\mathrm{ns}}-H_{\mathrm{s}}-\frac{G}{\left(1-P_{\mathrm{v}}\right)}$

Finally, $G$ can be estimated as a fraction $\left(C_{G}\right)$ of the soil contribution to the net radiation (Choudhury et al., 1987):

$G=C_{G}\left(1-P_{\mathrm{v}}\right) R_{\mathrm{ns}}$

where $C_{G}$ can vary in a range of $0.2-0.5$ depending on the soil type and moisture.

\section{Results}

\subsection{Radiometric temperatures}

Growth cycle of the sorghum plants was captured by interpolation from the periodic measurements taken over the course of the experiment. A third order regression equation was used for the canopy height (Fig. 2a). For the fraction cover, measured values also fitted a third order equation for $P_{\mathrm{v}}<1$, whereas a constant value of $P_{\mathrm{v}}=1$ was assumed from DOY 200 to the end of the experiment (Fig. 2b). Under these conditions of full vegetation coverage the two-source scheme becomes a single-source approach, with the vegetation as the only component exchanging energy with the atmosphere. Then, $T_{\mathrm{R}}=T_{\mathrm{c}}$ in Eq. (2), and transpiration is responsible of the total ET of the crop system. Also, differences between $T_{\mathrm{c}}$ and $T_{\mathrm{a}}$ are less than $1{ }^{\circ} \mathrm{C}$ for non-stressed canopies, which yields minor values for the sensible heat flux. Under these conditions $\lambda E T$ becomes the dominant flux in the right term of Eq. (1). Since soil temperature measurements were not available in this study, for partial cover conditions we assumed $T_{\mathrm{c}} \sim T_{\mathrm{a}}$ and $T_{\mathrm{S}}$ was inferred from Eq. (2) together with the measured $T_{\mathrm{R}}$ values.

Apogee IRT measurements were corrected for emissivity and atmospheric effect using the radiative transfer equation adapted to ground measurements (Sánchez et al., 2008). Values of $\varepsilon_{\mathrm{c}}=0.985 \pm 0.011$ and $\varepsilon_{\mathrm{s}}=0.960 \pm 0.013$ were used for this study (Rubio et al., 2003). Effective surface emissivity, $\varepsilon$, was calculated following the method proposed by Valor and Caselles (1996) (see Fig. 2b). The downwelling long-wave radiance, required for the atmospheric correction, was determined from the IRT values registered by the second Apogee pointing to the sky (Rubio, 1998).

Temperatures of the sunlit and shaded portions of a component (soil or vegetation) differ some degrees. Thanks to the wide field of view of the Apogee radiometers, and their deployment configuration over the sorghum, measured values of $T_{\mathrm{R}}$, and estimated values of $T_{\mathrm{s}}$, accounted for both sunlit and shaded portions of the soil and canopy.

Figure 3 shows four examples of the diurnal evolution of the gradient $T_{\mathrm{R}}-T_{\mathrm{a}}$, representative of different vegetation cover conditions: two for intermediate vegetation cover when the soil component is still visible (DOY 184, 185), and two for full cover conditions (DOY 229, 236). Furthermore, these four examples are also representative of a variety of cloud cover conditions: one cloud-free day (DOY 236), one fully overcast day (DOY 229), and a couple of partially cloudy days (DOY 184, 185). Surface temperature was generally warmer than air temperature during the middle of the 


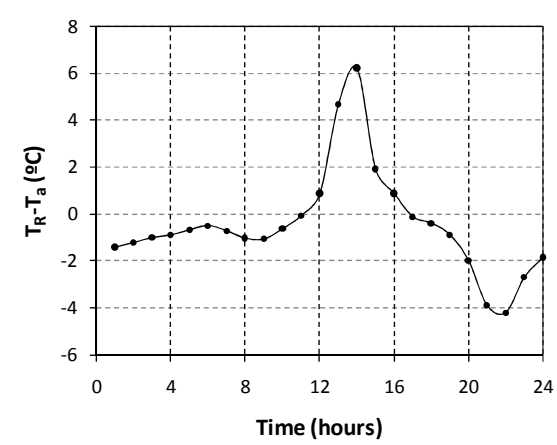

(a)

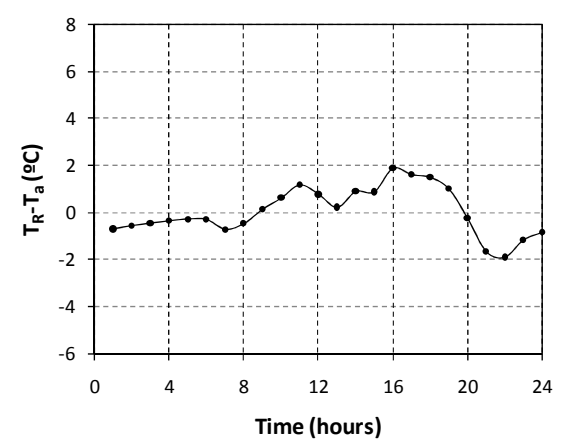

(c)

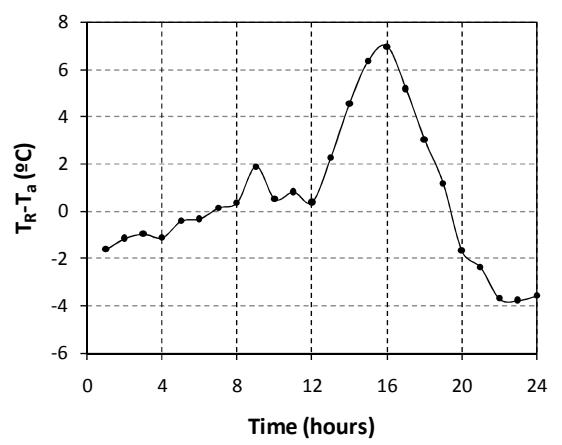

(b)

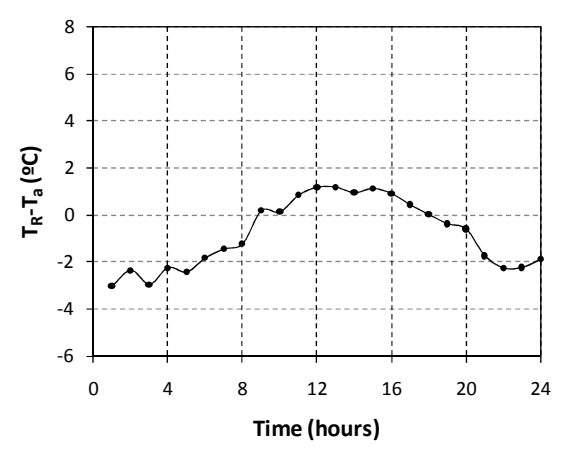

(d)

Fig. 3. Diurnal evolution of the gradient between sorghum radiometric temperature and air temperature: (a) DOY 184, (b) DOY 185, (c) DOY 229, (d) DOY 236.

day. This difference was minimum for full vegetation cover conditions $\left(<1^{\circ} \mathrm{C}\right)$, and increased with the amount of soil exposed (Fig. 3). Irrigation was scheduled according to the water loss determined by the lysimeter throughout the growing season to ensure enough water availability for transpirational cooling, avoiding plant water-stress and then warming of the canopy temperature. At night, thermal inversion appeared and surface temperature was $2-3^{\circ} \mathrm{C}$ cooler than air temperature. This difference can be even higher for rainfall or irrigation events. These temperature gradients control the exchange of $\mathrm{H}$ between the surface and the atmosphere, adding or reducing energy to the available $R_{\mathrm{n}}$.

\subsection{Modelled ET}

Surface temperature was used, together with registered solar radiation and downwelling long-wave radiation, to calculate $R_{\mathrm{n}}$ from Eqs. (5) and (6). Values 0.13 and 0.23 (Castrignanò et al., 1997) were used for the soil and canopy albedo, respectively, although possible changes in albedo are possible. Wind speed measurements from the adjacent weather station (representative of the values over the sorghum due to the flat terrain and the 60-min temporal averages used) were used to calculate the aerodynamic resistances required in Eqs. (3) and (4). These resistances together with the surface and air temperature data yielded $H$ results. A value of $C_{G}=0.2$, appropriate for wet soils (Choudhury et al., 1987), was assumed in Eq. (12) to estimate $G$ values.

Figure 4 shows hourly values of all flux components in Eq. (1). Note that, as a residual of the EBE, $\lambda E T$ is principally controlled by $R_{\mathrm{n}}$ and modulated by $H$. For our study period most available energy was partitioned to $\lambda \mathrm{ET}$. $\mathrm{H}$ was the dominant term for first weeks after planting, when the fraction cover was still very low, but unfortunately measure of $T_{\mathrm{R}}$ started on DOY 174 and data are not available for that period.

Values of latent heat flux were converted in ET values, dividing by the latent heat of vaporization, $\lambda$, and compared to ET water loss registered by the lysimeter. Figure 5 shows four examples of the diurnal evolution of these hourly ET values. STSEB estimations of ET match the measured ET values under a wide range of vegetation cover fractions and cloudy sky conditions. Note that energy balance models yield ET values also under rainfall or irrigation conditions when the lysimeter measure is compromised. Two examples of this effect can be observed in plots $5 \mathrm{~b}$ and $5 \mathrm{c}$, where ET 


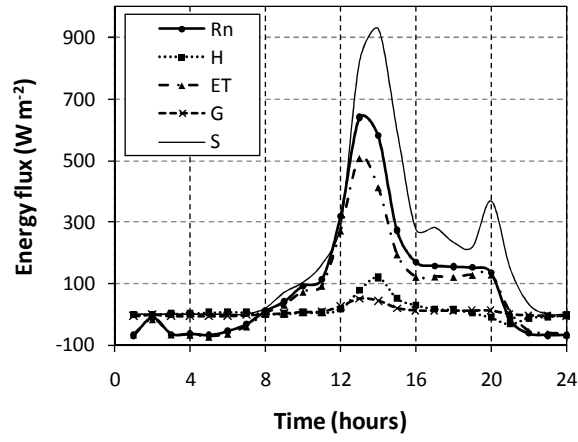

(a)

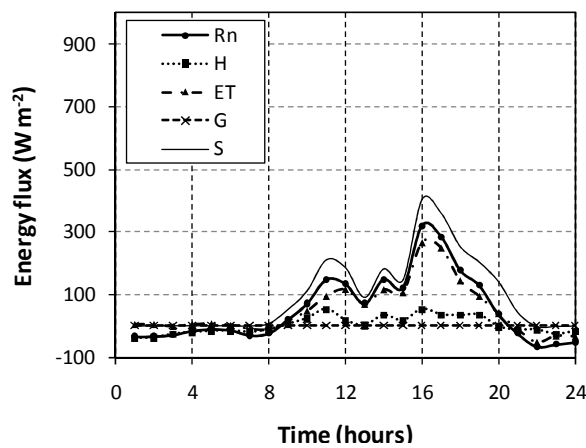

(c)

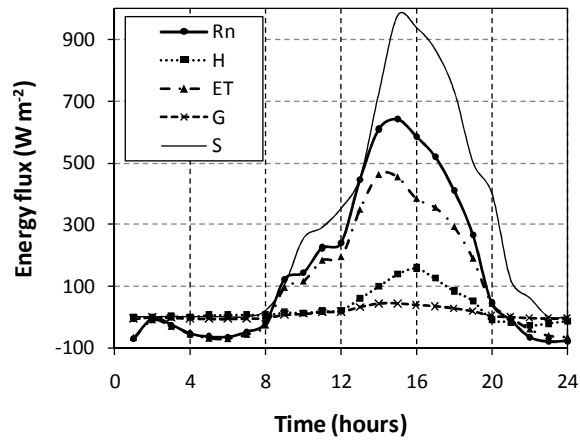

(b)

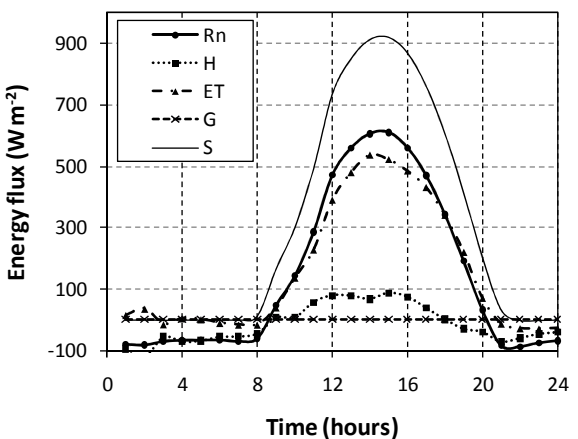

(d)

Fig. 4. Diurnal evolution of the sorghum flux components of the energy balance equation, together with the solar global radiation: (a) DOY 184, (b) DOY 185, (c) DOY 229, (d) DOY 236.

measured drops as a consequence of an irrigation event after 22 hours DOY 185 and due to a rainfall event between 12 and $15 \mathrm{~h}$ DOY 229, respectively. Also, the quick response of the energy balance models to changes in environmental conditions can be observed in DOY 184, in which after a cloudy morning the sky clears between 12 and $14 \mathrm{~h}$ before getting cloudy again (Fig. 4a). Figure 5a shows how modelled ET values peak for this interval, consequence of the increase in available net radiation, whereas measured ET does not.

Since night-time ET was generally negligible, hourly averages between 7 and $21 \mathrm{~h}$ were used for the quantitative test of the STSEB model. With this filtering we tried to avoid events such as irrigation (around midnight) or early morning dew. Rainfall events were also excluded from the hourly analysis. More than 1000 single observations were used for the comparison of the diurnal ET values (Fig. 6a). Besides the linear regression, the accuracy of prediction was quantified using the Root Mean Square Deviation (RMSD) between estimated and measured ET values. The systematic deviation was illustrated by the biased estimator (Bias), and the relative error by the Mean Absolute Percentage Difference (MAPD) (Willmott, 1982). Figure 6a shows the overall good agreement between modelled and measured instantaneous ET values. STSEB model tended to slightly overestimate and underestimate highest and lowest ET values, respectively. However, on average STSEB model reproduced lysimeter hourly ET measurements with negligible systematic deviation, and a RMSD of $\pm 0.14 \mathrm{~mm} \mathrm{~h}^{-1}$. Thus, a relative error of $22 \%$ was obtained for instantaneous ET.

Beyond the performance of a model at an instantaneous scale, what is really important from the point of view of the irrigation planning or the water saving is the capacity of a model to estimate daily ET values, and further cumulative water loss by evapotranspiration. Figure 7 shows the evolution of the daily ET values modelled and measured for the experiment duration. For a first stage, when the energy balance was still influenced by the exposed soil surrounding the sorghum plants, the average trend of daily ET was to increase with the vegetation fraction cover. Daily ET peaked by middle July, with values reaching $10 \mathrm{~mm} \mathrm{~d}^{-1}$, and then decreased until beginning of September. Lowest daily ET values, close to $2 \mathrm{~mm} \mathrm{~d}^{-1}$, were observed for some cloudy and rainy days by middle August. A total of 73 days were used for the quantitative comparison, with the only exclusion of rainy days with registered rainfall amounts over $5 \mathrm{~mm}$. Modelled values underestimated by $0.3 \mathrm{~mm} \mathrm{~d}^{-1}$ lysimeter daily ET measurements, with a RMSD of $\pm 1.0 \mathrm{~mm} \mathrm{~d}^{-1}$ (Fig. 6b). Thus, a relative error of $12 \%$ was obtained for daily ET. A similar 


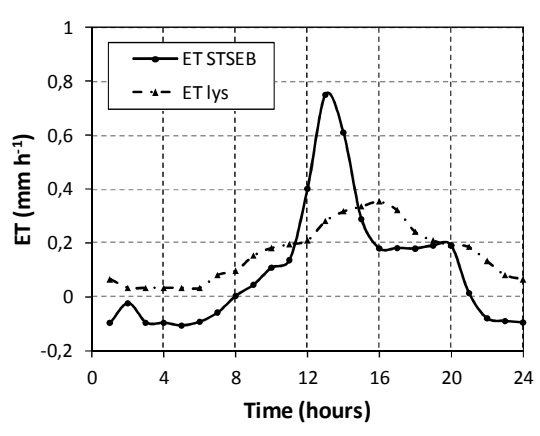

(a)

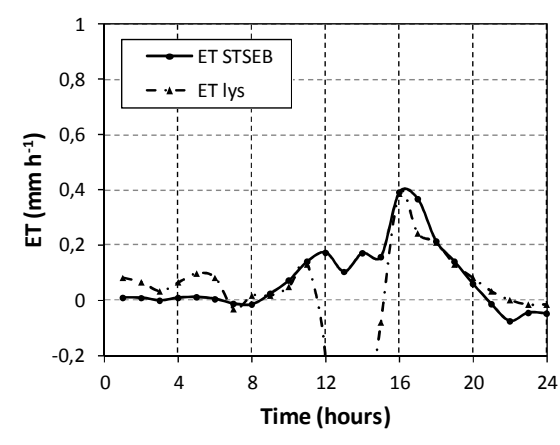

(c)

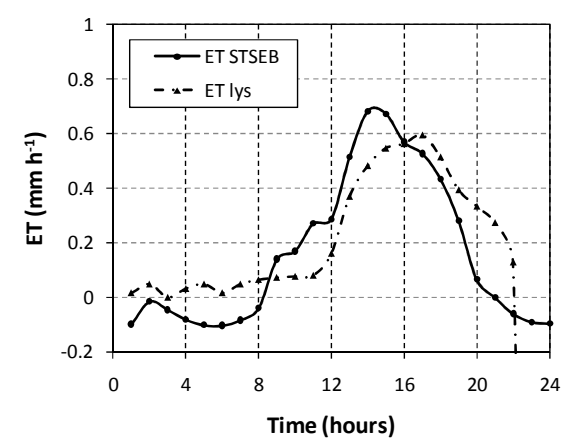

(b)

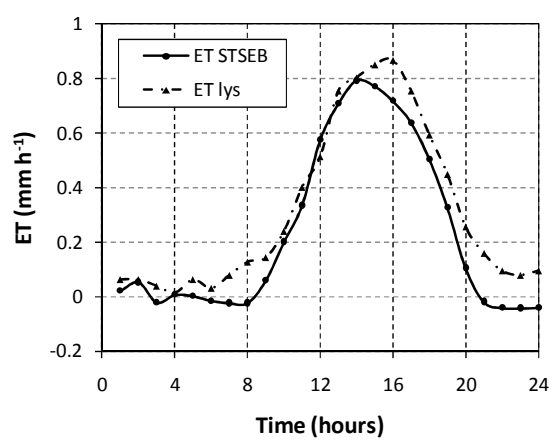

(d)

Fig. 5. Diurnal evolution of the estimated and measured sorghum ET: (a) DOY 184, (b) DOY 185, (c) DOY 229, (db) DOY 236.

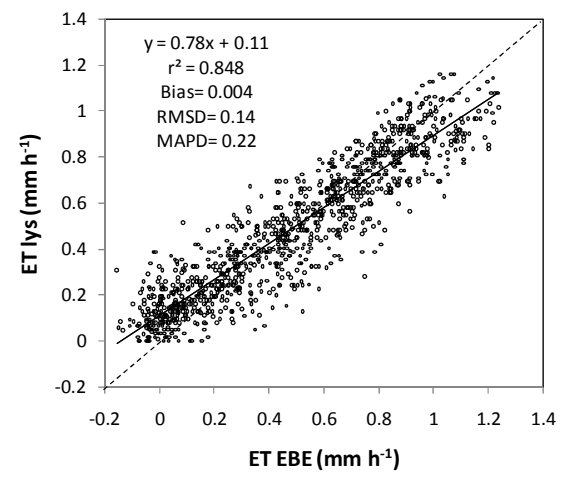

(a)

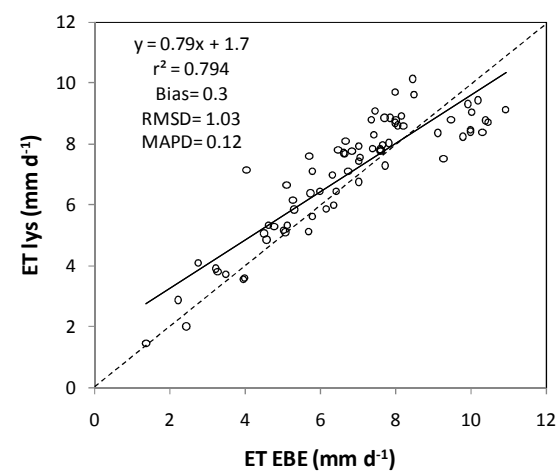

(b)

Fig. 6. Modelled (STSEB) versus measured (lys) sorghum evapotranspiration: (a) hourly values, (b) daily values. Results of the linear regression fit, together with the main statistics of the comparison (Bias, RMSD, and MAPD), are also included.

RMSD value of $\pm 0.9 \mathrm{~mm} \mathrm{~d}^{-1}$ and underestimation of $6 \%$ was observed when daily ET values were calculated using the standard FAO56 methodology (Allen et al., 1998).

These results are in agreement with some recent works. For instances, Kato and Kamichika (2006) used a dual crop coefficient to estimate ET in a sorghum field. Comparison with Bowen Ratio energy balance method showed a RMSD value of $\pm 0.84 \mathrm{~mm} \mathrm{~d}^{-1}$.

Figure 8 illustrates the growing season rainfall and irrigation along with the modelled and measured cumulative 


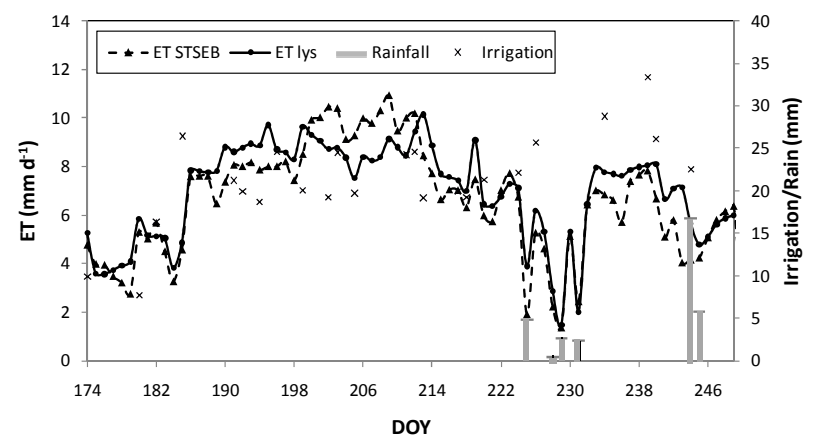

Fig. 7. Evolution of the sorghum daily ET values modelled (STSEB) and measured (lys) for the experiment duration. Rainfall and irrigation water quantities are also plotted.

ET. For the 75-day period studied in this work a total ET of $524 \mathrm{~mm}$ was measured by the lysimeter, very close to the $500 \mathrm{~mm}$ estimated from the STSEB model together with sorghum radiometric temperatures as input. For the same period, the total rainfall registered was $33 \mathrm{~mm}$, and a total irrigation of $506 \mathrm{~mm}$ was applied. Thus, cumulative ET obtained by the STSEB model underestimated $5 \%$ the lysimeter register.

These results illustrate the ability of surface temperature together with energy balance to estimate both short-term and long-term ET rates, and then to determine crop water necessity and schedule crop irrigation. This study will be further completed with the application to other biofuel crops such as sunflower and maize, with particular emphasis on their sparse growth phase.

\section{Conclusions}

This work was motivated by an increasing production of energetic crops in semi-arid regions and the need to determine their water requirements. This study focused on the evaluation of a two-source energy model to estimate crop water necessities from radiometric temperature information in a forage sorghum field. Two IRT radiometers were used, together with meteorological data, to run the STSEB model. Measurements in a weighing lysimeter were used to test modelled ET values at both, hourly and daily scales. For a variety of $P_{\mathrm{V}}$ and weather conditions, sorghum ET estimations were generally good, and even both very high and very low ET values were quite well captured by the model. Average errors of $22 \%$ and $12 \%$ were obtained for hourly and daily ET values, respectively, and total cumulated ET for the study period was underestimated by $5 \%$.

These results confirm STSEB model as an alternative to water balance techniques to determine short-term and long-term accurate actual evapotranspiration. The presented methodology could be then used to estimate ground-truth ET values, as an alternative to weighing lysimeters, required

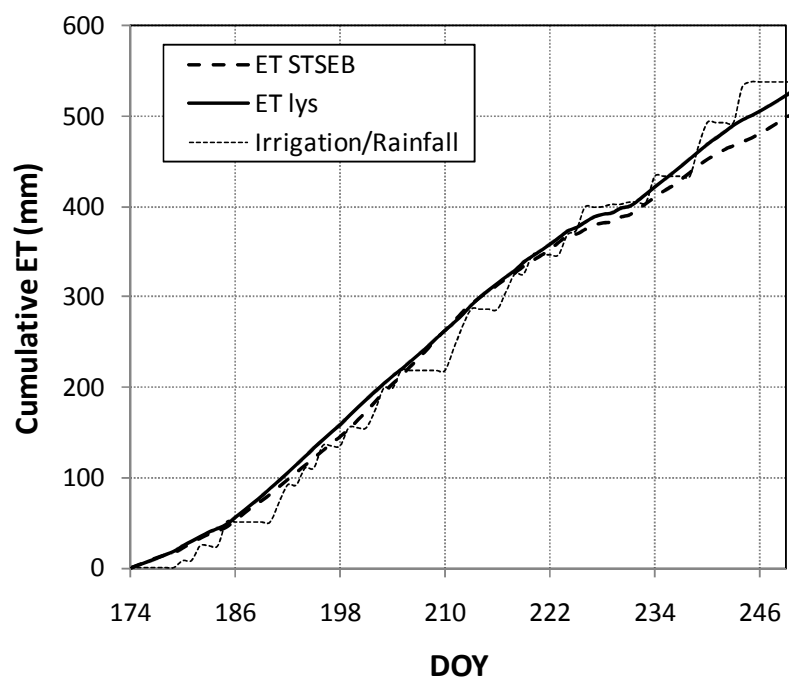

Fig. 8. Cumulative modelled (STSEB) and measured (lys) sorghum ET. Cumulative rainfall and irrigation applied is also plotted.

to determine irrigation needs or to calibrate crop coefficient based algorithms.

Acknowledgements. This work has been funded by the Spanish Science and Innovation Ministry (projects AGL2009-13124, CGL2010-17577, and CSD2008-00040, and Juan de la Cierva contract of J. M. Sánchez), Generalitat Valenciana (project PROMETEO/2009/086) and the JCCM (projects PEIC11-0170-8185 and PPII10-0319-8732). The authors would like to thank the logistical support in operating and maintaining the instrumentation of Laura Martínez, Angel García and Miguel Gómez. Also, the authors express their gratitude to the Regional Development Institute of the University of Castilla-La Mancha for providing the IRTs.

Edited by: N. Basu

\section{References}

Allen, R. G., Pereira, L. S., Raes, D., Smith, M.: Crop evapotranspiration: guidelines for computing crop water requirements. In: Proceedings of the Irrigation and Drainage Paper No. 56. Food and Agricultural Organization, United Nations, Rome, 1998.

Bashir, M. A., Hata, T., Tanakamaru, H., Abdelhadi, A. W., and Tada, A.: Satellite-based energy balance model to estimate seasonal evapotranspiration for irrigated sorghum: a case study from the Gezira scheme, Sudan, Hydrol. Earth Syst. Sci., 12, 11291139, doi:10.5194/hess-12-1129-2008, 2008.

Bastiaanssen, W. G. M., Menenti, M., Feddes, R. A., and Holtslag, A. A. M.: A remote sensing surface energy balance algorithm for land (SEBAL): 1. Formulation, J. Hydrol., 212-213, 198-212, 1998.

Castrignanò, A., Di Bari, V., and Stelluti, M.: Evapotranspiration predictions of CERES-Sorghum model in Southern Italy, Eur. J. Agron., 6, 265-274, 1997. 
Choudhury, B. J. and Idso, S. B.: Evaluating plant and canopy resistances of field grown wheat from concurrent diurnal observations of leaf water potential, stomatal resistance, canopy temperature, and evapotranspiration flux, Agr. Forest Meteorol., 34, 67-76, 1985.

Choudhury, B. J., Idso, S. B., and Reginato, R. J.: Analysis of an empirical model for soil heat flux under a growing wheat crop for estimating evaporation by an infrared-temperature based energy balance equation, Agr. Forest Meteorol., 39, 283-297, 1987.

Faver, K. L. and O'toole, J. C.: Short-term estimation of sorghum evapotranspiration from canopy temperature, Agr. Forest Meteorol., 48, 175-183, 1989.

Gardner, B. R., Nielsen, D. C., and Shock, C. C.: Infrared thermometry and the crop water-stress index:1. History, theory, and base-lines, J. Prod. Agric., 5(4), 462-466, 1992.

Gavilán, P. and Berengena, J.: Accuracy of the Bowen ratio-energy balance method for measuring latent heat flux in a semiarid advective environment, Irrigation Sci., 25, 127-140, 2007.

González-Dugo, M. P., Moran, M. S., Mateos, L., and Bryant, R.: Canopy temperatura variability as an indicator of crop water stress severity, Irrig. Sci., 24, 233-240, 2006.

Hall, F., Huemmrich, K., Goetz, S., Sellers, P. and Nickerson, J.: Satellite remote sensing of surface energy balance: Success, failures and unresolved issues in FIFE, J. Geophys. Res., 97, 1906119089, 1992.

Hatfield, J. L., Perrier, A., and Jackson, R. D.: Estimation of evapotranspiration at one time-of-day using remotely sensed surface temperatures, Agr. Water Manage., 7, 341-350, 1983.

Jackson, R. D., Idso, S. B., Reginato, R. J., and Pinter, P. J.: Canopy temperature as a crop water stress indicator, Water Resour. Res., 17, 1133-1138, 1981.

Jackson, R. D., Hatfield, J. L., Reginato, R. J., Idso, S. B. and Pinter, P. J.: Estimation of evapotranspiration from one time-of day measurements, Agr. Water Manage., 7, 351-362, 1983.

Kato, T. and Kamichika, M.: Determination of a crop coefficient for evapotranspiration in a sparse sorghum field, Irrig. Drain., 55, 165-175, 2006.

Kustas, W. P. and Norman, J. M.: Use of remote sensing for evapotranspiration monitoring over land surfaces, Hydrolog. Sci. J., 41, 495-516, 1996.

Li, F., Kustas, W. P., Prueger, J. H., Neale, C. M. U., and Jackson, T. J.: Utility of Remote Sensing based two-source energy balance model Ander low and high vegetation cover conditions, J. Hydrometeorol., 6, 878-891, 2005.

López-Urrea, R., Martín de Santa Olalla, F., Fabeiro, C., and Moratalla, A.: Testing evapotranspiration equations using lysimeter observations in a semiarid climate, Agric. Water Manage., 85, 15-26, 2006.

López-Urrea, R., Martín de Santa Olalla, F., Montoro, A., and López-Fuster, P.: Single and dual crop coefficients and water requirements for onion (Allium cepa L.) under semiarid conditions, Agr. Water Manage, 96, 1031-1036, 2009a.

López-Urrea, R., Montoro, A., López-Fuster, P., and Fereres, E.: Evapotranspiration and responses to irrigation of broccoli, Agr. Water Manage., 96, 1155-1161, 2009b.
López-Urrea, R., Montoro, A., González-Piqueras, J., LópezFuster, P., and Fereres, E.: Water use of spring wheat to raise water productivity, Agr. Water Manage., 96, 1305-1310, 2009c.

MARM: 2009: Anuario de Estadística 2010 (http://www.marm.es/ es/estadistica/temas/anuario-de-estadistica/2010/default.aspx? parte=3\&capitulo=13\&grupo=5), Consultation: July 29, 2011. Montoro, A., López-Fuster, P., and Fereres, E.: Improving on-farm water management through an irrigation scheduling service, Irrigation Sci., doi:10.1007/s00271-010-0235-3, 2010.

Montoro, A., López-Fuster, P., and Fereres, E.: Improving on-farm water management through an irrigation scheduling service, Irrig. Sci., doi:10.1007/s00271-010-0235-3, in press, 2010.

Moran, M. S., Clarke, T. R., Inoue, Y., and Vidal, A.: Estimating crop water deficit using the relation between surface-air temperature and spectral vegetation index, Remote Sens. Environ., 49, 246-263, 1994.

Norman, J. M., Kustas, W., and Humes, K.: A two-source approach for estimating soil and vegetation energy fluxes from observations of directional radiometric surface temperature, Agr. For. Meteorol., 77, 263-293, 1995.

Piccini, G., Ko, J., Marek, T., and Howell, T.: Determination of growth-stage-specific crop coefficient $\left(\mathrm{k}_{c}\right)$ of maize and sorghum, Agr. Water Manage., 96, 1698-1704, 2009.

Pinter, P. J., Hatfield, J. L., Shepers, J. S., Barnes, E. M., Moran, M. S., Daughtry, C. S. T., and Upchurch, D. R.: Remote sensing for crop management, Photogramm. Eng. Rem. S., 69, 647-664, 2003.

Rubio, E.: Optimising the remote sensing measurement of temperature and emissivity, $\mathrm{Ph} \mathrm{D}$. Thesis, University of Valencia, 272 pp., 1998.

Rubio, E., Caselles, V., Coll, C., Valor, E., and Sospedra, F.: Thermal infrared emissivities of natural surfaces: Improvements on the experimental set-up and new measurements, Int. J. Remote Sens., 20, 5379-5390, 2003.

Sánchez, J. M., Kustas, W. P., Caselles, V., and Anderson, M.: Modelling surface energy fluxes over maize using a two-source patch model and radiometric soil and canopy temperature observations, Remote Sens. Environ., 112, 1130-1143, 2008.

Sánchez, J. M., Caselles, V., Niclòs, R., Coll, C., and Kustas, W. P.: Estimating energy balance fluxes above a boreal forest from radiometric temperature observations, Agr. For. Meteorol., 149, 1037-1049, 2009.

Su, Z.: The Surface Energy Balance System (SEBS) for estimation of turbulent heat fluxes, Hydrol. Earth Syst. Sci., 6, 85-100, doi:10.5194/hess-6-85-2002, 2002.

Valor, E. and Caselles, V.: Mapping Land Surface Emissivity from NDVI: Application to European, African, and South American Areas, Remote Sens. Environ., 57, 167-184, 1996.

Wang, D. and Gartung, J.: Infrared canopy temperature of earlyripening peach trees under postharvest deficit irrigation, Agric. Water Manage., 97, 1787-1794, 2010.

Willmott, C. J.: Some comments on the evaluation of model performance, Bull. Am. Meteorol. Soc., 63, 1309-1313, 1982. 